\title{
Política, poder e as implicações de gênero
}

Paula Caldas Brognoli

E-mail: paulacbrognoli@hotmail.com Universidade Tecnológica Federal do Paraná, Curitiba, Paraná, Brasil

Maria Sara de Lima Dias

E-mail: msaradldias@gmail.com Universidade Tecnológica Federal do Paraná, Curitiba, Paraná, Brasil

\begin{abstract}
RESUMO
Neste artigo objetivou-se identificar como as mulheres percebem o poder ao estarem em um cargo político. Justifica-se o interesse por abordar as mulheres na política devido à pouca representatividade destas em espaços de poder, ainda que a simples representação de mulheres em espaços eminentemente masculinos não signifique, automaticamente, gerar elementos emancipatórios. É uma pesquisa qualitativa e se escolheu entrevistar as mulheres atuantes na municipalidade e duas no âmbito federal para realizar a pesquisa. Como estratégias de investigação utilizaram-se os seguintes procedimentos: observação e registro do comportamento das mulheres no ambiente de trabalho e entrevistas semiestruturadas. Como resultados tem-se o seguinte perfil das sete entrevistadas: seis com nível superior e uma com nível fundamental completo, cinco são casadas e com filhos, e uma solteira e outra divorciada sendo uma delas com filho. Da observação das rotinas na câmara (órgão legislativo) e no acompanhamento das sessões foi possível identificar que as mulheres em geral são vítimas de constrangimentos frequentes de seus pares com maior poder hierárquico. As mulheres que ocupam cargos na política foram capazes de identificar a importância do poder em suas relações cotidianas, das sete entrevistadas cinco correlacionam o poder com o tipo de trabalho desenvolvido e identificam práticas de assédio. Como considerações finais destaca-se que é preciso estimular uma maior participação política feminina uma vez que somente a presença da mulher nestes ambientes já significa uma atitude de oposição a uma cultura machista de relações de poder majoritariamente masculino. 0 problema da falta de poder e das tentativas de deslegitimar a presença feminina nas rotinas da câmara pode ser enfrentado com o apoio e união das mulheres em torno de seus direitos, demonstrando assim uma outra possibilidade do enfrentamento às práticas de assédio nos espaços políticos, e em um sentido mais amplo em outras dimensões da vida social da mulher na política.
\end{abstract}

PALAVRAS-CHAVE: Mulheres. Poder. Política. Trabalho. 


\section{INTRODUÇÃO}

As temáticas da política e do gênero são fundamentais para que se estabeleça no país uma democracia paritária. É ainda necessário que candidatos e candidatas estejam a favor dos direitos das mulheres e exerçam o mandato político para transformação da realidade de exclusão e limitação de direitos humanos das brasileiras. Tendo em conta que os direitos humanos são historicamente regulados mediante lutas sociais, os diferentes movimentos feministas é que permitiram denunciar o silenciamento das mulheres na política bem como as diferentes violações à dignidade humana. Deste modo, o que se quer é muito mais do que uma paridade democrática: o que se quer é fortalecer os direitos das mulheres, para dar visibilidade às diferenças e possibilitar políticas protetivas para que a mulher possa exercer sua liberdade de escolhas e realizar todos os seus direitos, como por exemplo, de viver livre da violência, ir à escola, participar da tomada de decisões, bem como, receber salários iguais para trabalhos iguais. A introdução deve conter a motivação para a pesquisa, o objetivo e a metodologia aplicada na realização da pesquisa.

A presença da mulher na política significa uma atitude da pessoa em se opor a uma cultura historicamente estabelecida onde a relação de domínio e o poder é em geral exercido pelo homem. "É necessário superar concepção corrente de que a formalização da igualdade e a proibição normativa da discriminação são suficientes para garantir a igualdade real de condições e oportunidades entre homens e mulheres" (QUINTELA; DIAS, 2016, p. 53). A igualdade de gênero pode começar com a representação política. A importância da paridade de gênero para a democracia tem sido apontada pelas organizações internacionais e faz parte da agenda das Nações Unidas que almeja garantir a implementação, em nível local, dos Objetivos de Desenvolvimento Sustentável (ODS) ${ }^{1}$.

Garantir a participação plena e efetiva das mulheres e a igualdade de oportunidades para a liderança em todos os níveis de tomada de decisão na vida política, econômica e pública e adotar e fortalecer políticas sólidas e legislação aplicável para a promoção da igualdade de gênero e o empoderamento de todas as mulheres e meninas em todos os níveis são algumas das metas globais do Objetivos de Desenvolvimento Sustentável (ODS) 5 - Igualdade de Gênero.

A ONU Mulheres ${ }^{2}$ alerta que um regime democrático justo e inclusivo que permite às mulheres liderar e participar de forma substantiva e igualitária da tomada de decisão, junto com os homens, para contribuir com a agenda pública com perspectiva de gênero. De modo que é uma mudança de paradigma societal no qual se leva em consideração a definição encontrada nos dicionários, vemos que "paridade" refere-se à característica do que é igual ou semelhante, o que podemos ligar ao Artigo 113, inciso 1 da Constituição Federal, em que diz: "todos são iguais perante a lei". Ao analisarmos, no entanto, o histórico das leis brasileiras, notamos que na Constituição de 1824 a mulher sequer era citada como participante da sociedade. Apenas em 1934, passados mais de 100 anos, a mulher começa a ganhar sua paridade com a definição de cidadania. Vemos os direitos políticos evoluindo e englobando o sexo feminino, além da legalização de algumas causas como o desquite, caracterizado como ato jurídico pelo qual se dissolve a sociedade conjugal.

No Brasil, a ONU Mulheres apoia a participação política de mulheres em todos os espaços de poder, formais e não formais, garantindo a sua diversidade e o 
fortalecimento dos movimentos de mulheres e feministas: negras, indígenas, ciganas, rurais, jovens. Um dos maiores marcos da paridade de gênero no Brasil ocorreu no ano de 1943 com a consolidação das leis trabalhistas, em que homens e mulheres veem seu trabalho revisto e regulamentado. Tais leis ainda possuem 27 artigos em vigor, oferecendo proteção ao trabalho feminino. Vale lembrar que antes, em alguns casos, a mulher casada precisava apresentar uma carta de autorização do esposo, afirmando que o mesmo permitia tal trabalho. A partir de então, nem homem nem mulher precisam apresentar cartas autorizando o trabalho, ainda que fossem casados.

A ONU Mulheres, lançou, no ano de 2018 uma web série sobre igualdade entre homens e mulheres na política. Sendo que a produção audiovisual discute as responsabilidades dos partidos políticos e do eleitorado, bem como a importância da paridade de gênero para a democracia, tendo em vista as eleições de 2018. Essas ações apresentadas pela ONU Mulheres, permitem maior visibilidade e ajudam a construir uma sociedade mais igual.

Ao pesquisar sobre a participação das mulheres na política brasileira através do site da Scielo com os descritores: política, poder e gênero, não identificamos nenhum artigo, no entanto, a pesquisa com as palavras compostas gênero e política ou participação eleitoral e política pública permitiram localizar alguns trabalhos.

A busca pelo Scielo, foi a seguinte: através das palavras mulheres e poder, foram encontrados 39 artigos, mulheres e política foram encontrados 43, mulheres, política e trabalho foram encontrados 11 artigos e destes selecionados os mais recentes, desde 2014 abordando aqueles que dizem respeito a paridade de gênero e política.

Segundo, Rosângela Saldanha Pereira (2010) pesquisadoras investigaram sobre as desigualdades existentes entre mulheres e homens evidenciadas por indicadores socioeconômicos aponta que os programas e ações governamentais concebidos e executados sem a adoção da perspectiva de gênero são um dos elementos que impedem a concretização do princípio de igualdade de oportunidades. A incorporação da transversalidade de gênero nas políticas públicas no Brasil é recente, assim como os estudos e a avaliação dos orçamentos públicos.

Para Lena Lavinas (2016) ao debater alguns pontos desenvolvidos no mais recente relatório das Nações Unidas intitulado Avanços do Mundo das Mulheres 2015-2016 trabalha com a persistência das desigualdades de gênero no mundo contemporâneo. A autora explorou aspectos ligados às consequências das políticas macroeconômicas ortodoxas na reprodução dessas desigualdades por restringir o gasto público e as políticas universais.

O poder tem múltiplas definições dependendo do campo de conhecimento em que à análise do conceito e do conteúdo do poder se estabelece. $O$ poder este que também pode ser expresso nas nossas relações sociais cotidianas, em diferentes formas e circunstâncias, instituídas como, por exemplo, o poder familiar, o poder nas empresas, escolas, etc. Diante de um espaço político em que há existência do poder, uma das formas demostradas pelo fato de se ter o poder é cometida pelo gênero masculino em forma de assédio, seja moral, sexual com mulheres que ocupam o mesmo cargo político. $O$ assédio sendo uma forte 
implicação de gênero, pode ser um dos causadores da pouca participação de mulheres no meio político.

Algumas formas de poder podem ser julgadas ou legitimadas pelo/a executor/a da ordem como o poder do/a chefe sobre o/a subordinado/a, outras formas de exercício do poder podem se relacionar com algum tipo de violência. Assim a atribuição do poder a um Indivíduo sobre o outro, pode contribuir para que este se torne um/a agressor/a. No sentido de desenvolver ações voltadas a defender seus próprios interesses, deste modo utilizando de seu poder para dominar o outro.

Segundo José H. Faria \& Francis K.Meneghetti $(2002$, p. 4) “A violência está ligada a toda a forma de exploração e dominação". Existem muitas maneiras de manifestar a violência, seja ela física, psíquica, social, entre outras que prejudicam a vítima no seu mundo, afetando no ambiente de trabalho e na sua vida como um todo.

A mulher situada em diferentes marcadores sociais e pertencendo a diferentes grupos sociais ou classe social, geracional, etnia/raça, gênero sofre de diversas formas de violência. Demandando formas diferentes de proteção social não só em seu ambiente de trabalho, mas também em diferentes espaços de relação social. Pode-se afirmar que existe a violência entre casais na qual a mulher em sua maioria é a vítima; a violência nas relações familiares nas quais a mulher novamente é a vítima principalmente na relação parental. Historicamente a ocupação dos espaços sociais pela mulher envolve padrões sociais e culturais de normas nas quais existem lugares permitidos e proibidos, conforme Luciana Panke (2016). A mulher estaria incluída em alguns lugares como no lar, na fábrica e excluída de outros lugares que envolve o poder como na política. Assim, as mulheres permanecem em constante luta por seus lugares de direito, como na busca de sua representatividade na política. A violência seja psicológica, física, pode estar caracterizado como uma implicação de gênero, em que se usa violência como forma de expressar o poder e exercer sobre o gênero feminino.

Para Luana Bandeira Amaral et al (2016, p. 534) "A violência contra as mulheres é um fenômeno complexo, polissêmico e controverso". Apesar de programas como o de políticas públicas que protegem as mulheres, ainda a violência atinge mulheres em diferentes contextos de vulnerabilidade.

Um dos programas de políticas públicas que atendem as mulheres em situações de violência, servindo de auxílio para proteger as mulheres, é a Lei 11.340/0 chamada Lei Maria da Penha. Segundo, Alessandra Acosta Carneiro \& Cristina Kologeski Fraga (2012, p. 370) "A lei emerge como uma possibilidade jurídica para resguardar os direitos da mulher, a qual apregoa que a violência doméstica e familiar contra a mulher constitui uma das formas de violação dos direitos humanos". A lei é o resultado de um longo processo de lutas de mulheres para que outras pudessem ter seus direitos. A lei traz uma reflexão para a sociedade de que a violência é uma realidade e precisa ser combatida, através da ajuda do estado. Através de maior representatividade feminina no campo político, se possibilita maior chance de ser discutido e implementado programas voltados para políticas públicas para mulheres.

Os programas que atendem as mulheres vítimas de violência vêm trazendo para a sociedade o reconhecimento de que o problema da violência contra a mulher é uma questão da vulnerabilidade do gênero. Explicando este fenômeno, 
Roberta de Alencar Rodrigues (2014, p. 4) diz: "A violência de que a mulher padece se trata pelo fato de ser mulher e que produz o seu sofrimento físico, sexual e ou psicológico".

Esta violência ocorre no cotidiano como espaço de poder, para Maritza Montero (2010) é preciso também analisar a prática do poder na vida cotidiana e nas relações do sujeito com a comunidade, o poder é exercido. De qualquer forma, as assimetrias das relações humanas, são determinadas por lugares sociais, onde um sujeito exerce algum tipo de opressão sobre o outro de forma desigual. Segundo Panke (2016, p. 73, grifos da autora) “O desenvolvimento histórico do 'ser mulher' se associou diretamente as relações de poder, em que o machismo e o patriarcado defendem a dominação do sexo masculino", ou seja, defendem o poder do homem sobre a mulher.

Considerando todos estes espaços e ambientes de relação interpessoal e social nos quais as mulheres podem sofrer a violência, a presença da mulher na política também se revela como mais um espaço no qual se pode praticar atos de violência. Ao demonstrar a relação entre política e poder temos que:

\begin{abstract}
A violência contra as mulheres na política não apenas ameaça os compromissos nacionais e internacionais para que a tomada de decisões seja equilibrada em termos de gênero, mas também afeta a integridade da democracia (KROOK; RESTREPPO, 2016, p. 157).
\end{abstract}

Diferentes formas de políticas públicas podem ser implementadas no sentido de gerar maior igualdade, mesmo no caso das empresas, as relações de trabalho podem ser mediadas por normas e padrões de comportamentos adequados. Para Mallado Mimbrero (2017, p. 425, tradução livre) "Modelos de implementação de integração de gênero e de aplicação de instrumentos políticos, tais como certificações de igualdade de gênero em organizações ${ }^{4 \prime \prime}$.

Segundo Simone Lolatto, et al (2016), o desafio de eleger mais mulheres comprometidas com o avanço de políticas públicas para melhorar a vida das mulheres se associa à persistência em continuar reivindicando condições de igualdade na sociedade. Por meio de políticas públicas para mulheres tem-se a possibilidade de focar em programas voltados para as mulheres amenizando os conflitos de gênero.

Entre tantos alcances dos movimentos feministas, segundo Jussara Prá (2014, p. 171) um dos alcances foi que "permitiu difusão de um feminismo de alcance internacional que fomentou a defesa dos direitos humanos das mulheres e sua transposição para cenários regionais e nacionais" que surge com a luta pelo direito ao voto, igualdade das mulheres que incorporou uma gama extensa de reinvindicações e que teve três grandes momentos, final do século XIX até começo do século XX, como uma das pioneiras e figura significativa nesse período no Brasil, Bertha Lutz é conhecida como a maior líder na luta pelos direitos políticos das mulheres brasileiras.

Para Ana Rita Duarte (2009) é preciso relembrar o nome de outras protagonistas dos movimentos feministas e de suas histórias como Maria Ernestina Carneiro Santiago Manso Pereira (ou Mietta Santiago), que foi a primeira mulher no país a exercer, plenamente, os seus direitos políticos: o de votar e o de ser votada. Laudelina de Campos Melo, fundadora do primeiro sindicato de trabalhadoras domésticas do Brasil, a atuação dela é tida como fundamental para 
o reconhecimento dos direitos da categoria. Terezinha Zerbini, ativista de direitos humanos brasileira, fundadora e líder do Movimento Feminino pela Anistia.

As feministas da segunda onda do feminismo, entre 1960 e 1970, veem as desigualdades culturais e políticas das mulheres como intrinsecamente ligadas e incentivam as mulheres a entender os aspectos de suas vidas pessoais como profundamente politizados e como o reflexo de estruturas de poder sexistas.

O terceiro momento se inicia entre 1990 a 2000 no qual se deve destaque a Maria da Penha que lutou para que seu agressor fosse condenado. Maria da Penha é líder de movimentos de defesa dos direitos das mulheres, vítima da violência doméstica, e mulher inspiradora e de luta para tantas outras mulheres. Os desafios são muitos para vencer estereótipos de gênero e o preconceito instalado na sociedade. Segundo Women in Parliaments, vamos precisar em torno de 47 anos para estarmos pareadas na representação política, uma vez que hoje em todo o mundo temos $22 \%$ de representatividade nos parlamentos. Para chegarmos à paridade, de muitas gerações vamos precisar contar, com mulheres de luta, persistência em lutar pelos direitos de todas.

Para Betânia Gonçalves (2009), a participação das mulheres na política interfere na vida pública, pois estas debatem e legislam sobre temas que não são prioridades, ou nunca são colocados em pauta pelos homens, como exemplo, maior participação das mulheres na política, violência de gênero, dentre outros assuntos que as mulheres, estando na política, podem apresentar novos temas e legislar sobre questões não consideradas pelos homens.

O direito ao voto representa um grande avanço na história das mulheres brasileiras, uma vez que até o século XX, na maioria dos países, quem votava eram homens, e especialmente homens brancos e ricos e não se admitia sequer a ideia de que as mulheres estivessem atuando na esfera pública, essa ideia foi rejeitada por séculos. A assimilação desta cultura de exclusão se estendia por toda a sociedade. A compreensão de que uma mulher pode ter o mesmo poder que um homem para tomar decisões e ajudar uma sociedade a se desenvolver é algo recente em nossa história.

Segundo Ana Rita Duarte (2009) é nesse mesmo período do século XX, que se pode observar transformações com o movimento das sufragistas. Algumas mulheres foram importantes neste processo. Uma delas foi Nísia Floresta considerada uma pioneira do feminismo no Brasil que rompeu os limites entre os espaços públicos e privados. Ela atuou publicando textos em jornais, além de ter dirigido um colégio para moças no Rio de Janeiro e escreveu livros em defesa dos direitos das mulheres, dos índios e dos escravos. Entre tantas outras destaca-se o nome de Maria Amélia de Queiroz, que também lutou pelos direitos das mulheres.

Segundo Ana Maria Carneiro Araújo (2014) no Brasil, inúmeras mudanças ocorreram em diversos setores na sociedade e um deles foi o sistema político que permitiu alguns avanços nas organizações de luta. Um exemplo o surgimento de um partido, Partido Republicano Feminino, tendo como presidenta Leolinda Daltro, o qual, se propunha a lutar pelos direitos das mulheres. No entanto, o enfrentamento para se obter uma emenda à Constituição que atendesse as reinvindicações dependeu de muitos embates. Por exemplo, nessa época, ocorreram campanhas contra as mulheres, que eram ridicularizadas e expostas como incapazes de ocupar postos eletivos públicos. Finalmente passados 18 anos, no ano de 1928, a primeira mulher conseguiu ser eleitora e prefeita no estado do 
Rio Grande do Norte. Esta foi Celina Guimarães Viana, um exemplo de mulher a alcançar o poder. Carlota Pereira de Queiroz da Rocha, por sua vez, foi eleita no ano de 1934 pelo Estado de São Paulo, em que permaneceu no cargo entre 1934 e 1935, se tornando assim, a primeira deputada federal da história do Brasil.

Deste modo as questões de gênero precisam ser analisadas em todos os contextos, uma vez que a exploração e o processo discriminatório permanecem. A temática do gênero vai muito além da questão de ser mulher ou homem,

As questões de gênero perpassam a organização social e estabelecem os locais adequados para os indivíduos. Além das questões biológicas o gênero significa uma construção cultural que estabelece comportamentos esperados a partir das diferenças biológicas (PANKE, 2016, p. 73).

Associado às questões de gênero se relacionam dimensões sobre a questão do poder e do assédio. A igualdade da mulher pode ser pensada à partir de sua representação política, no entanto, por si só, não é o cargo que tem relação direta com a visão da busca pela igualdade de gênero. Ocorre que muitas mulheres em cargo de poder pouco se preocupam com às questões das lutas feministas. Um outro fato é o de que a relação de poder é um fator inerente à vida em sociedade. O poder, quase sempre, é exercido sem que a parte submissa perceba, na maioria das vezes, o poder é imperceptível. A sutileza no exercício do poder é um fator importante na relação de mando, pois envolver a parte submissa na engrenagem dominante como se fosse parte do todo, como se o projeto dominante fosse dela, é a melhor maneira de dar ao poder constituído uma eficácia duradoura.

\begin{abstract}
A participação com paridade de gênero na política é fundamental. Não só na estrutura partidária, mas a paridade precisa ser instituída nas secretarias municipais e estaduais e no ministério federal. A equidade de gênero precisa ser implementada também nos altos Tribunais do Poder Legislativo e até nas diretorias das empresas privadas. No processo eleitoral, é preciso garantir a paridade nas listas eleitorais e paridade no acesso aos recursos da campanha eleitoral (ALVES, 2016, p. 59).
\end{abstract}

Para Alexandre Piffero Spohr (2016) Uma das possíveis soluções para se ter um ambiente democrático na política é o sistema de cotas que pode ser uma ação de elevar a representação das mulheres na política. Essas ações afirmativas incluem a capacitação de mulheres, a provisão de incentivos financeiros e o estabelecimento de espaços organizacionais específicos para a promoção da participação feminina.

Segundo Luciana Panke (2016, p. 202) "Políticas afirmativas de inclusão das mulheres nos espaços eletivos de representação e na gestão pública parecem ser alternativas para gerar empoderamento e visibilidade". Através de políticas focadas nas mulheres para atingir uma maior participação em espaços de poder, como na política são necessárias para quem sabe se ter a possibilidade de alcançar igualdade de gênero, sendo exercido a democracia em espaço de até então, predominância masculina.

A mais de 20 anos de cota para mulheres para todas as eleições proporcionais estabelecendo um percentual mínimo de $30 \%$ e máximo de $70 \%$ para candidaturas de cada sexo (Lei 9.504/97). A medida, no entanto, não representa um avanço na ocupação feminina de cargos políticos nem a defesa de pautas destinadas às mulheres, isto porque as candidaturas não garantem uma eleição efetiva. Ocorreu 
avanço, pois percebe-se mulheres na política, mas ainda se precisa avançar muito para se alcançar a igualdade nesse espaço tão importante na sociedade.

A importância de se ter mais mulheres ocupando cargos políticos, vem da necessidade de se ter mais políticas públicas voltadas para as diferentes mulheres, com visão interseccional de raça, classe social e gênero, muito embora a simples ocupação do cargo não remeta diretamente a uma preocupação de cunho feminista acredita-se que através desta perspectiva, ao se ter mais mulheres ocupando espaços políticos, poderia se alcançar maior representatividade e mais luta em defesa de causas e projetos voltados para a mulher.

As cotas de representação significaram um grande avanço na luta das mulheres por representação e espaços de decisões políticas, porém ter apenas candidatas não é o suficiente, é preciso que mais mulheres sejam eleitas, para que mais políticas públicas sejam pensadas por e para mulheres, visando trazer um fim ao sistema patriarcal e á série de opressões enfrentadas por elas (SALGADO, 2015, p. 170-171).

Para José Ernesto Pimentel Filho \& Mariana Ramos Rodrigues (2017) as leis que objetivam proporcionar maior participação política das mulheres são fundamentais. Essa participação ainda é muito pequena, quando comparado ao número de homens que ocupam cargos políticos. Os autores argumentam que o ideal era ter metade das vagas sendo ocupadas por mulheres, mas a lei apresenta uma cota de candidatas, que é necessária para ser pelo menos o começo de uma construção mais igualitária também no campo da política. Tal ocupação permitiria em tese que mais pautas direcionadas às mulheres fossem votadas como as pautas do combate à diferentes formas de violências e preconceitos existentes, no campo do trabalho.

Para Maria Sara de Lima Dias (2016) as discussões acerca da igualdade entre homens e mulheres no mercado de trabalho, muitas vezes, são deslegitimadas por críticas atribuídas ao seu desempenho nas mesmas funções profissionais, que os homens, ainda havendo o que se chama de preconceito de gênero em determinadas áreas do saber. Portanto, é fundamental pesquisar o perfil da mulher no mercado de trabalho inclusive em suas atividades de trabalho na política.

Dentre os inúmeros desafios enfrentados pelas mulheres quando se filiam a algum partido, encontra-se a falta de recurso para suas campanhas, e aquelas que vencem uma eleição, sofrem novamente no meio político, vivenciando as implicações de gênero, como assédio, violência, entre outras formas de silenciar a mulher, silenciar a voz feminina.

\section{METODOLOGIA}

Este estudo objetivou identificar como as mulheres percebem o poder ao estarem em um cargo político. Enquanto justificativa o interesse por abordar as mulheres na política se dá pela pouca representatividade destas em espaços de poder, ainda que a simples representação de mulheres nestes espaços e/ou em redutos eminentemente masculinos não significa que, automaticamente, se vá gerar elementos emancipatórios de equidade e dignidade, no entanto, a presença das mulheres na política pode afetar de diferentes modos os quadros atuais no poder. Quanto ao tipo de investigação trata-se de uma pesquisa qualitativa e 
exploratória como instrumentos de coleta de dados foram utilizados diário de campo para as observações em gabinetes na Câmara Municipal de Curitiba e roteiro de questões para as entrevistas. Considera-se que o diário de campo foi escolhido com a intencionalidade de registrar as mulheres em seu dia a dia na atividade política junto a seus pares. E as entrevistas semiestruturadas como procedimento de coleta de informação privilegiada para obter a percepção das mulheres sobre o seu trabalho. Foram realizadas entrevistas semiestruturadas com as mulheres ocupantes de cargos políticos eletivos que se interessaram pelo tema e aceitaram, de forma voluntária, participar da pesquisa sobre a participação de mulheres na política. As entrevistas foram realizadas com sete mulheres que trabalham na política ( 5 vereadoras e 2 deputadas federais) em seus gabinetes e tiveram duração em média de 30 minutos.

Para preservar a privacidade das participantes utilizaremos nomes fictícios para identificar as participantes. A escolhas dos nomes se deu, através de nomes fictícios.

\section{RESULTADOS E DISCUSSÕES}

Tabela 1 - Distribuição do perfil das mulheres entrevistadas

\begin{tabular}{|c|c|c|c|c|c|c|c|}
\hline $\begin{array}{l}\text { Perfil das } \\
\text { entrevistadas }\end{array}$ & Idade & Escolaridade & $\begin{array}{l}\text { Estado } \\
\text { Civil }\end{array}$ & $\begin{array}{l}\text { Filho } \\
\mathrm{s}\end{array}$ & $\begin{array}{l}\text { Parti } \\
\text { do }\end{array}$ & $\begin{array}{l}\text { Ocupação } \\
\text { Profissional }\end{array}$ & $\begin{array}{l}\text { Se sofreu } \\
\text { assédio }\end{array}$ \\
\hline Frida & 53a. & $\begin{array}{l}\text { Superior } \\
\text { Comp. }\end{array}$ & Solteira & Não & PT & $\begin{array}{l}\text { Professora } \\
\text { Cargo: } \\
\text { Vereadora }\end{array}$ & Sim \\
\hline Maria & 56 a. & $\begin{array}{l}\text { Superior } \\
\text { Comp. }\end{array}$ & Casada & Sim & $\begin{array}{l}\text { PMD } \\
\text { B }\end{array}$ & $\begin{array}{l}\text { Gestora } \\
\text { Pública } \\
\text { Cargo: } \\
\text { Vereadora }\end{array}$ & Não \\
\hline Joana & $64 a$. & $\begin{array}{l}\text { Fundamental } \\
\text { Incomp. }\end{array}$ & Casada & Sim & $\mathrm{PP}$ & $\begin{array}{l}\text { Empresária } \\
\text { Cargo: } \\
\text { Vereadora }\end{array}$ & Não \\
\hline Angela & 58a. & $\begin{array}{l}\text { Superior } \\
\text { Comp. }\end{array}$ & $\begin{array}{l}\text { Divorciad } \\
\text { a }\end{array}$ & Sim & PV & $\begin{array}{l}\text { Médica } \\
\text { Legista } \\
\text { Cargo: } \\
\text { Vereadora }\end{array}$ & Sim \\
\hline Lélia & $48 a$. & $\begin{array}{l}\text { Superior } \\
\text { Comp. }\end{array}$ & Casada & Sim & $\begin{array}{l}\text { PCdo } \\
\text { B }\end{array}$ & $\begin{array}{l}\text { Servidora } \\
\text { Pública } \\
\text { Cargo; } \\
\text { Deputada } \\
\text { Federal }\end{array}$ & Sim \\
\hline Dandara & $55 a$. & $\begin{array}{l}\text { Superior } \\
\text { Comp. }\end{array}$ & Casada & Sim & PDT & $\begin{array}{l}\text { Servidora } \\
\text { Pública } \\
\text { Cargo: } \\
\text { Vereadora }\end{array}$ & $\mathrm{Sim}$ \\
\hline Nísia & $57 a$. & $\begin{array}{l}\text { Superior } \\
\text { Comp. }\end{array}$ & Casada & Sim & PR & $\begin{array}{l}\text { Professora e } \\
\text { Empresária } \\
\text { Cargo: } \\
\text { Deputada } \\
\text { Federal }\end{array}$ & Sim \\
\hline
\end{tabular}

Fonte: Dados da pesquisa- Elaboração própria

A tabela 1 mostra o perfil das 7 entrevistadas para este artigo e evidencia que a maioria delas tem nível superior de ensino, são casadas e tem filhos. Portanto, exercem, além da política, trabalhos em diferentes espaços sociais, como esposas, mães e cuidadoras da casa, responsáveis também por atividades domésticas. Aqui se permite inferir e problematizar sobre a participação das mulheres, uma vez que são elas que assumem uma sobrecarga de funções. Sua luta e participação na vida 
política estaria, portanto, limitada. As condições e possibilidades para bem representar toda a categoria de mulheres são permeadas por papéis que a sociedade e a cultura patriarcal impõem às mulheres.

A participação das mulheres de forma ativa nos diferentes espaços ocupacionais e setores da sociedade são indispensáveis para a construção da democracia e da cidadania. O poder que a mulher precisa exercer deve ser construído por meio de movimentos sociais, debates, lideranças, bem como, pela ocupação de cadeiras parlamentares.

Quando questionada sobre a sua percepção sobre a baixa participação da mulher na política a participante Maria argumenta que:

O porquê a mulher não vota em mulher, prefere passar a sua representatividade para um homem. Quero fazer uma campanha, "mulher vota em mulher".

Tal expressão cunhada pela participante demonstra, em relação ao poder político, por um lado, o sentimento de que a mulher não fortalece a sua representatividade, por outro lado, também expressa o seu desejo de mudança. Sua crença de que campanhas publicitárias podem alterar a opinião pública e ampliar o apoio a candidaturas femininas. Uma campanha dirigida às mulheres poderia contribuir, encorajando mais mulheres a entrar para política e assim, influenciando de maneira ativa a participação de mulheres na política permitindo assim, a igualdade. Débora Diniz, em entrevista concedida para Gabriel Hirabahasi (2018), afirma que a baixa representatividade das mulheres na política, sendo que elas são mais de $50 \%$ da população brasileira, está relacionada à expectativa que se tem de que quem deve ocupar os cargos políticos são os homens. Enquanto isso não mudar, de acordo com Débora, nem as mulheres votarão nas mulheres.

Os homens sempre exerceram o poder político. Na história da legislação eleitoral mundial as mulheres não tinham direito nem ao voto, menos ainda à representatividade, a ser votada. No Brasil, o direito ao voto às mulheres só foi obtido no ano de 1932, depois de muita luta das mulheres. "O decreto no 21.076, de 24 de fevereiro de 1932, regulamentava o alistamento e o processo eleitoral no país, nos âmbitos federal, estadual e municipal, trazendo uma série de inovações, dentre as quais se destacava o estabelecimento do sufrágio universal e secreto" (ARAÚJO, 2003, p. 135).

Quando questionadas sobre se já sofreram assédio sexual ou moral as entrevistadas descrevem de que forma este se apresenta nos espaços políticos.

Existe sim, assédio sexual e moral dentro da câmara, e por ser um espaço de poder em que tem hierarquia, essa questão acaba piorando. (Entrevistada Frida)

Uma vez que o poder é exercido em um espaço relacional, que é normatizado pelas instituições que organizam a sociedade, o assédio tanto moral quanto sexual também se manifesta no poder público. Conforme Maria Cristina Cescatto Bobroff (2013, p. 252) "O assédio moral caracteriza-se pela submissão do trabalhador a constantes humilhações e constrangimentos".

No caso do poder público a hierarquia acaba agravando as manifestações do assédio, pois, "o agressor pode engrandecer-se rebaixando o outro, sem culpa e sem sofrimento; trata-se da perversão moral" (FREITAS, 2001, p. 9), fazendo com que a vítima se sinta culpada e gerando sofrimento intenso. Deste modo, "A vítima 
do assédio é penalizada individualmente pelo sofrimento vivido". (SILVA, 2015, p. 590).

O assédio mesmo no ambiente público gera culpa, e aliado ao sentimento de solidão do/a assediado/a surge o medo da denúncia uma vez que o poder na câmara e no senado é baseado em relacionamentos. Nas organizações existem diferentes tipos de estrutura que vão desde as instituições extremamente hierarquizadas até as lineares, conforme a entrevistada Angela,

A questão de hierarquia e por estar no mesmo nível de poder é menos evidenciada.

Ou seja, mesmo em cargo político a hierarquia é algo em que o poder é mais utilizado. Por exemplo, um político com sua assessora, pode exercer sua hierarquia para utilizar o poder. Para Antonio Martiningo Filho, $(2008$, p. 16) "O processo de assédio moral no trabalho traz sérios prejuízos para o indivíduo, para a organização e para a sociedade"). E ainda complementa: "A desorganização de algumas empresas pode facilitar a implantação de estado de cerco ou assédio, pois é sempre geradora de estresse, quer se trate de inadequada definição dos papéis, de falta de coordenação dos trabalhos ou de falta de suporte gerencial por parte da administração".

Quando questionadas sobre: como as mulheres (deputadas e vereadoras) agem diante do comportamento dos homens, quando são assediadas, as respostas foram:

Muitas delas sofrem constrangimentos e não fazem política, uma vez que é um meio duro, machista. (Entrevistada Angela)

O assédio pode vir como constrangimento que é uma forma de inibir a expressão subjetiva do sujeito, assim o meio político utiliza do autoritarismo com uma forma de controle para evitar a representatividade feminina. Em tal espaço relacional o poder e o assédio já estão incorporados em nossa cultura a muito tempo. Por outro lado, observamos uma maior representatividade feminina na política na contemporaneidade (JARDIM, 2012).

A percepção do aumento quantitativo da presença de mulheres nos espaços políticos é importante, pois sinaliza que revoluções simbólicas pouco visíveis estão acontecendo nas categorias de pensamento da sociedade contemporânea ou nas convenções cognitivas, mesmo que não tenham, ainda, se expressado no mundo objetivo.

Quando questionadas sobre por que, a senhora acha que ainda se tem poucas mulheres ocupando cargos públicos? Em seu depoimento Maria informou que:

A um sentimento comportamental das mulheres, precisa haver uma conscientização. As mulheres precisam se integrar com a sociedade, participação mais ativa, sendo líder comunitária, participando de sua comunidade para que essas ações possam fomentar para que cheguem no parlamento. A mulher prefere transferir para um homem aquilo que ela poderia fazer por ela, poderia pensar na questão da valorização da mulher.

Ao votar em um homem, transfere seu poder a ele que não representa e não luta pelos direitos das mulheres, como uma mulher pode lutar. O que se vê na política, principalmente brasileira é que o machismo vem calando as mulheres que já estão na esfera política e impedindo e excluindo outras mulheres deste meio. 
Muitas mulheres vão se silenciando por medo, por já terem sofrido várias formas de violência e intimidação que pode ser violência física, psicológica, patrimonial, intelectual e simbólica, em que o outro manipula seu comportamento, sua forma de agir e pensar.

Existe uma cota de $30 \%$ que o partido estabelece para que mulheres possam disputar cargos políticos, no entanto isso não ocorre, a realidade é bem distante e os outros $70 \%$ fazem inscrição para concorrer aos cargos, falta investimento do partido para as mulheres. (Entrevistada Maria)

A perda de poder já se inicia quando os partidos designam apenas $30 \%$ das vagas, que é expresso por lei, para se candidatar aos cargos de decisão, como se fosse um favor que os partidos fazem, sendo que o democrático seria ter $50 \%$ destinados às mulheres a ocuparem esses espaços de poder não só o espaço de candidaturas. Cabe destacar que muitos partidos inscrevem mulheres como candidatas apenas para cumprir a lei, porém não oferecem condições para que elas realmente participem da eleição em condições de ganhar.

As mulheres têm dificuldade de entrar para política e, quando entram, enfrentam situações como a descrita por Lélia

\begin{abstract}
Vivemos em uma sociedade machista e muitas vezes sentimos que não somos respeitadas pelos demais parlamentares como iguais ou não somos escutadas em nossos pleitos e colocações. Isso é muito preocupante. Inclusive há um estigma que há uma pauta de mulher e uma pauta de homem, onde a parte que cabe aos representantes do parlamento que são mulheres são ligadas à seguridade, á maternidade e à infância..
\end{abstract}

A participação da mulher na política foi, e continua sendo, uma das conquistas mais difíceis e tardias que tivemos em relação aos direitos das mulheres. Segundo Rein Venegas (2013, p. 225) "A participação política das mulheres em postos de representação é muito necessária, por razões de democracia, de representação de interesses, entre outras já assinaladas" ${ }^{5}$. Mesmo sendo a maioria em termos de população temos inúmeras dificuldades de conseguir cargos políticos. O ranking mundial de participação de mulheres em cargos do Executivo realizado pela ONU mulheres mostra que o Brasil está 1670 lugar dos 174 países analisados. Esta posição é muito desconfortável e reflete que este ainda se constitui em reduto masculino, e por que não dizer, em espaço de homens brancos.

Hoje no Brasil (2019), a representatividade no Congresso Nacional está com 55 mulheres para 513 homens, isso chega á míseros $10,7 \%$, e no Senado temos 13 mulheres para 81 cadeiras no parlamento, nosso que resulta em pouco mais de $12 \%$. Ao utilizar a mesma análise para comparar a representatividade de mulheres na Câmara Municipal de Curitiba, das 38 cadeiras, as mulheres ocupam apenas oito, que representa $21 \%$ do total. Com estes números como é possível pensar que as questões femininas serão pautadas, analisadas e aprovadas? As mulheres devem ser respeitadas pelas suas diferenças e é com ênfase nelas que se advoga a sua maior representação na política.

"As relações de poder, portanto, podem ser utilizadas como um conceito pelo qual se permite mapear as relações de gênero e as disputas sociais a elas relacionadas" (CAPPELLE, 2010, p. 81). A questão de disputas, gênero e poder são originárias de uma construção social e histórica, em que os homens se posicionam de diversas formas, utilizando o espaço de poder muitas vezes para se sentirem 
melhores e causarem constrangimentos, já as mulheres em sua defesa tentam ter estratégias para impedir que machismo chegue a elas de forma tão forte e opressora. Muitas se calam, usam o silêncio como estratégia de sobrevivência, já outras lutam e se unem, como exemplo as feministas. Observa-se que nesta legislatura um grupo de mulheres jovens e negras conseguiu alcançar uma vaga na câmara federal e trouxeram consigo um novo olhar sobre o cenário nacional, bem como, a esperança de que mais mulheres ocupem este espaço.

Para Luciana Panke (2016, p. 203), é preciso naturalizar a mulher como candidata, como eleita, como legisladora ou administradora pública. Para, quem sabe, a sociedade observar a mulher como possibilidade e com capacidade para ocupar este espaço de poder. O desejo de avanço democrático entende uma sociedade em que homens e mulheres tenham as mesmas oportunidades, a mesma voz. É fundamental saber compartilhar, somar e respeitar para termos uma sociedade mais igual para todos/as. No caso específico do Brasil, esta estrutura de dominação tem duas características muito particulares que provocam efeitos profundos nas formas de participação da mulher na vida pública: uma desigualdade social abismal e uma hierarquia rígida em relação ao acesso a direitos.

\section{CONSIDERAÇÕES FINAIS}

Neste artigo foram abordados alguns aspectos da participação das mulheres na política como: sentimento de que a mulher não fortalece a sua representatividade quando vota em um homem e deixa de ter uma mulher na política que represente e dê voz a causa das mulheres; a questão da igualdade de gênero em todos os campos da sociedade, derrubando os preconceitos e violências existentes e combatendo com os feminismos.

Ao analisar os dados da pesquisa percebeu-se consciência política por parte de algumas entrevistadas que estando em cargos de poder exercem sua função defendendo as causas femininas e representando as mulheres de forma ativa. As múltiplas formas em que o poder é exercido, sendo através de relacionamentos em espaço político, e o quanto o poder influência nas decisões e atua em várias formas de comportamento podendo favorecer as mulheres ou desqualificá-las também fizeram parte das análises.

De acordo com a pesquisa aqui apresentada se conclui que é preciso garantir a igualdade de gênero nos espaços de poder, provocando mudanças nas estruturas dos partidos políticos, a fim de garantirmos participação efetiva nos cargos de direção dos poderes Executivo e Legislativo em todos os âmbitos do governo (municipal, estadual e federal). Considerando que a maior participação política das mulheres depende da reestruturação da sociedade e não apenas de leis eleitorais é importante que haja ações políticas e sociais para formação de mulheres como líderes políticas e sociais, tornando-as, assim, cidadãs fortes, seguras, ativas e altivas, para que não reste espaço para os homens manipular e monopolizar o espaço político. Enquanto os homens com posicionamento machista e misógino ocuparem as posições político-decisórias, permanecerá a discriminação intencional ou estrutural das mulheres. É fundamental que as mulheres sejam protagonistas de suas próprias histórias, decidindo seu caminho e onde querem chegar. 
Deste modo se desenha um quadro com poucas mulheres na representação e na ocupação de cargos políticos. O perfil das mulheres entrevistadas é de pessoas com nível superior, casadas e com filhos. Em nosso modelo de democracia é preciso fomentar não só uma maior participação política feminina como uma maior consciência das disparidades de uma cultura machista e patriarcal mesmo entre as mulheres. Somente a maior preocupação com as temáticas do gênero na política seria capaz de transpor uma série de constrangimentos diários para a maior participação das mulheres na política.

Ao abordar as mulheres na política, a pouca representatividade destas se devem a estilos e expectativas que ainda são extremamente masculinos. Para alterar o processo eleitoral é preciso investir no processo educacional, alterar as representações das mulheres, ouvir as vozes ativas das mulheres nas escolas, nas comunidades e nos movimentos sociais. Formar politicamente as mulheres para que, futuramente, se tornem legítimas lideranças políticas capazes de estimular o voto de mulheres em mulheres e fazer uma política mais justa e democrática. 


\title{
Politics, power and the implications of gender
}

\begin{abstract}
The objective was to identify how women perceive power by being in political office. It justifies the interest in approaching women in politics and their lack of representation in spaces of power, although the simple representation of women in eminently masculine spaces does not automatically mean generating emancipatory elements. The methodology of qualitative research was chosen to interview the working women in the municipality, due to the proximity and facility to investigate the perceptions of the power. As research strategies, the following procedures were used: observation and recording of women's behavior in the work environment and interviews. As a result the following profile of the seven interviewees is found: six with a higher level and one with a complete fundamental level, five are married and have children, and one single and divorced, one of them with children. From the observation of the routines in the chamber (legislative body) and the follow-up of the sessions it was possible to identify that women in general are victims of frequent constraints of their peers with greater hierarchical power. Women in political positions were able to identify the importance of power in their day-to-day relationships. Of the five women interviewed, five correlated power with the type of work developed and also identified practices of harassment. As final considerations it is necessary to stimulate a greater female political participation since only the presence of women in these environments already means an attitude of opposition to a macho culture of relations of power mainly male. The problem of powerlessness and attempts to de-legitimize women's presence in the chamber's routines can be faced with women's support and union around their rights, thus demonstrating another possibility of coping with harassment practices in political spaces, and in a broader sense in other dimensions of women's social life in politics.
\end{abstract}

KEYWORDS: Woman. Power. Politics. Work. 


\title{
La política, el poder y las implicaciones del género
}

\author{
RESUMEN
}

El objetivo era identificar cómo las mujeres perciben el poder al ocupar cargos políticos. Justifica el interés por acercarse a las mujeres en la política y su falta de representación en los espacios de poder, aunque la simple representación de las mujeres en espacios eminentemente masculinos no significa automáticamente generar elementos emancipadores. La metodología de la investigación cualitativa fue elegida para entrevistar a las trabajadoras en el municipio, debido a la proximidad y facilidad para investigar las percepciones del poder. Como estrategias de investigación, se utilizaron los siguientes procedimientos: observación y registro del comportamiento de las mujeres en el entorno laboral y entrevistas. Como resultado, se encuentra el siguiente perfil de los siete entrevistados: seis con un nivel superior y uno con un nivel fundamental completo, cinco están casados y tienen hijos, y uno solo y divorciado, uno de ellos con hijos. A partir de la observación de las rutinas en la cámara (cuerpo legislativo) y el seguimiento de las sesiones, fue posible identificar que las mujeres en general son víctimas de frecuentes limitaciones de sus pares con mayor poder jerárquico. Las mujeres en posiciones políticas pudieron identificar la importancia del poder en sus relaciones diarias. De las cinco mujeres entrevistadas, cinco se relacionaron con el tipo de trabajo desarrollado y también identificaron prácticas de hostigamiento. Como consideraciones finales, es necesario estimular una mayor participación política femenina, ya que solo la presencia de mujeres en estos entornos ya significa una actitud de oposición a una cultura machista de relaciones de poder, principalmente masculinas. El problema de la impotencia y los intentos de deslegitimar la presencia de las mujeres en las rutinas de la cámara se puede enfrentar con el apoyo y la unión de las mujeres en torno a sus derechos, lo que demuestra otra posibilidad de hacer frente a las prácticas de acoso en los espacios políticos, y en un sentido más amplio en otras dimensiones de la vida social de las mujeres en la política.

PALABRAS CLAVE: Mujer. Poder. Política. Trabajo. 
${ }^{1}$ https://nacoesunidas.org/pos2015/

${ }^{2}$ http://www.onumulheres.org.br/areas-tematicas/lideranca-e-participacao/

${ }^{3}$ https://nacoesunidas.org/onu-lanca-webserie-sobre-igualdade-entre-homens-emulheres-na-politica/

4"Modelos de implementación del mainstreaming de género y los de aplicación de instrumentos políticos como las certificaciones de igualdad de género en las organizaciones".

5 "La participación política de las mujeres en puestos de representación es muy necesaria, por las razones de democracia, de representación de intereses, entre otras de las ya señaladas".

\section{REFERÊNCIAS}

ALENCAR-RODRIGUES, Roberta de; ESPINOSA, Leonor María Cantera. ¿Cómo mujeres inmigrantes enfrentan la violencia en la relación de pareja?. Estud. psicol. Natal, v. 19, n. 1, p. 4-12, Mar., $2014 . \quad$ Disponível em: <http://www.scielo.br/scielo. php?script=sci_arttext\&pid=S1413294X2014000100002\&Ing=en\&nrm=iso>. Acesso em: 08 set., 2017.

ALVES, José Eustáquio Diniz Alves. A mulher na política, despatriarcalização e envelhecimento: o crescente poder das balzaquianas. Revista Gênero, v. 14, n. 2, p. 51-66, 2016.

AMARAL, Luana Bandeira de Mello et al. Violência doméstica e a Lei Maria da Penha: perfil das agressões sofridas por mulheres abrigadas em unidade social de proteção. Rev. Estud. Fem., Florianópolis, v. 24, n. 2, p. 521-540, ago. 2016. Disponível em: <http://www.scielo.br/scielo.php?script=sci_arttext\&pid=S0104026X2016000200521\&lng=en\&nrm=iso>. Acesso em:1 4 Set. 2017.

ARAUJO, Ana Maria Carneiro. Apresentação. Cad. Pagu, n. 43, p. 7-12, 2014. Disponível em: <http://dx.doi.org/10.1590/0104-8333201400430007>. Acesso em 14 ago. 2017.

ARAUJO, Rita de Cássia Barbosa de. O voto de saias: a Constituinte de 1934 e a participação das mulheres na política. Estud. av., São Paulo, v. 17, n. 49, p. 133150, Dec. 2003.2 Disponível em: <http://www.scielo.br/scielo.php?script=sci_arttext\&pid=S010340142003000300009\&Ing=en\&nrm=iso>. Acesso em: 13 Mar. 2018.

BOBROFF, Maria Cristina Cescatto; MARTINS, Júlia Trevisan. Assédio moral, ética e sofrimento no trabalho. Rev. Bioét., Brasília, v. 21, n. 2, p. 251-258, aga. 2013. Disponível em: <http://www.scielo.br/scielo.php?script=sci_arttext\&pid=S198380422013000200008\&Ing=en\&nrm=iso>. Acesso em: 13 Mar. 2018. 
CAMINOTTI, Mariana. La representación política de las mujeres en el período democrático. Revista SAAP, v. 7, n. 2, p. 329-337, 2013. Disponível em: $<$ http://www.scielo.org.ar/scielo.php?script=sci_arttext\&pid=S1853$19702013000200011 \&$ Ing=es\&nrm=iso >. Acesso em 14 ago. 2017.

CAPPELLE, Mônica Carvalho Alves; MELO, Marlene Catarina de Oliveira Lopes. Mulheres policiais, relações de poder e de gênero na polícia militar de Minas Gerais. Rev. Adm. Mackenzie (Online), v. 11, n. 3, p. 71-99, 2010. Disponível em: $<$ http://www.scielo.br/scielo.php?script=sci_arttext\&pid=S167869712010000300006\&lng=en\&nrm=iso >. Acesso em 21 ago. 2017.

CARNEIRO, Alessandra Acosta; FRAGA, Cristina Kologeski. A Lei Maria da Penha e a proteção legal à mulher vítima em São Borja no Rio Grande do Sul: da violência denunciada à violência silenciada. Serv. Soc. Soc., São Paulo, n. 110, p. 369-397, jun, $2012 . \quad$ Disponível em: <http://www.scielo.br/scielo.php?script=sci_arttext\&pid=S010166282012000200008\&Ing=en\&nrm=iso>. Acesso em: 09 Mar. 2018.

DIAS, Maria Sara de Lima. A escolha feminina na área das profissões tecnológicas: impactos na subjetividade. Cad. Gên. Tecnol., Curitiba, v. 9, n. 33, p. 3-21, jan./jun. 2016.

DUARTE, Ana Rita Fonteles. Memórias em disputa e jogos de gênero: O Movimento Feminino Pela Anistia no Ceará (1976-1979). Anexo VI Florianópolis: Universidade Federal de Santa Catarina, 2009.

FARIA, José H, de; MENEGHETTI, Francis K. A Instituição da Violência nas Relações de Trabalho. In: ENANPAD, 2002, Salvador. XXVI Encontro Nacional da ANPAD, 2002. Anais da ENANPAD[CD-Rom].2002.

FREITAS, Maria Ester de. Assédio moral e assédio sexual: faces do poder perverso nas organizações. Rev. adm. empres., São Paulo, v. 41, n. 2, p. 8-19, jun 2001. Disponível em: <http://www.scielo.br/scielo.php?script=sci_arttext\&pid=S003475902001000200002\&Ing=en\&nrm=iso>. Acesso em: 13 Mar. 2018.

GIL, Antônio Carlos, Como elaborar projetos de pesquisa. - 4. ed. - São Paulo: Atlas, 2002.

GONÇALVES, Betânia Diniz. Impactos da participação e da consciência política na vida das mulheres líderes em política. Pesqui. prát. psicossociais, v. 3, n. 2, p. 199213, 2009.

HIRABAHASI, Gabriel. Nem mulheres votam em mulheres por causa de uma expectativa masculina, afirma antropóloga. Época. 2018. Disponível em: https://epoca.globo.com/nem-mulheres-votam-em-mulheres-por-causa-de-umaexpectativa-masculina-afirma-antropologa-22991167. Acesso em: 20 ago. 2018.

JARDIM, Maria A. Chaves J. Política e poder: mulheres presentes no Legislativo. Rev. Estud. Fem., v. 20, n. 3, p. 955-972, 2012. Disponível em: $<$ http://www.scielo.br/scielo.php?script=sci_arttext\&pid=S0104 
KROOK, Mona Lena; RESTREPO SANIN, Juliana. Género y violencia política en América Latina. Conceptos, debates y soluciones. Polít. gob, México, v. 23, n. 1, p. 127-162, jun. $2016 . \quad$ Disponível em: <http://www.scielo.org.mx/scielo.php?script=sci_arttext\&pid=S166520372016000100127\&lng=es\&nrm=iso>. Acesso em: 12 set. 2017.

LAVINAS, Lena. "É a macroeconomia, idiota!". Rev. Estud. Fem., Florianópolis, v. 24, n. 2, p. 621-627, Aug. $2016 . \quad$ Disponível em: $<$ http://www.scielo.br/scielo.php?script=sci arttext\&pid=S0104026X2016000200621\&lng=en\&nrm=iso>. Acesso em: 06 ago. 2018.

LOLATTO, Simone. Mulheres na política: Trajetórias da Vereadoras Titulares em Florianópolis/sc (Brasil). 2016. 348f. Tese (doutorado) - Universidade Federal de Santa Catarina, Centro de Filosofia e Ciências Humanas, Programa de PósGraduação Interdisciplinar em Ciências Humanas, Florianópolis, 2016.

LUSA, Mailiz Garibotti. Desconstruindo o heterocentrismo da violência nas relações conjugais. Rev. katálysis, Florianopolis, v. 11, n. 1, p. 149-151, jun. 2008. Disponível em: <http://www.scielo.br/scielo.php?script=sci_arttext\&pid=S1414$49802008000100016 \&$ Ing=en\&nrm=iso>. Acesso em: 08 set. 2017.

MACIEL, Débora Alves. Ação coletiva, mobilização do direito e instituições políticas: o caso da campanha da lei Maria da Penha. Rev. bras. Ci. Soc., São Paulo, v. 26, n. 77, p. 97-112, out. $2011 . \quad$ Disponível em: $<$ http://www.scielo.br/scielo.php?script=sci_arttext\&pid=S010269092011000300010\&lng=en\&nrm=iso>. Acesso em: 17 set. 2017.

MARTININGO FILHO, Antonio; SIQUEIRA, Marcus Vinicius Soares. Assédio moral e gestão de pessoas: uma análise do assédio moral nas organizações e o papel da área de gestão de pessoas. RAM, Rev. Adm. Mackenzie, São Paulo, v. 9, n. 5, p. 1134, $2008 . \quad$ Disponível em: $<$ http://www.scielo.br/scielo.php?script=sci_arttext\&pid=S167869712008000500002\&Ing=en\&nrm=iso>. Acesso em: 13 mar. 2018.

MENEGHEL, Stela. Nazareth. et al. Repercussões da Lei Maria da Penha no enfrentamento da violência de gênero. Ciênc. Saúde Coletiva, v. 18, n. 3, p. 691700, 2013.2 Disponível em: $<$ http://www.scielo.br/scielo.php?script=sci_arttext\&pid=S1413$81232013000300015 \&$ Ing=en\&nrm=iso>. Acesso em: 21 ago. 2017.

MIGUEL, Luis Felipe; QUEIROZ, Cristina Monteiro de. Diferenças regionais e o êxito relativo de mulheres em eleições municipais no Brasil. Rev. Estud. Fem., Florianópolis, v. 14, n. 2, p. 363-385, set. 2006. Disponível em: $<$ http://www.scielo.br/scielo.php?script=sci arttext\&pid=S0104026X2006000200003\&Ing=en\&nrm=iso>. Acesso em: 06 ago. 2018.

MIMBRERO MALLADO, Concepción; CANTERA ESPINOSA, Leonor María; SILVA, Joilson Pereira da. Aplicación del mainstreaming de género en las organizaciones a través de las certificaciones. Estud. psicol. (Campinas), Campinas, v. 34, n. 3, p. 
<http://www.scielo.br/scielo.php?script=sci_arttext\&pid=S0103-

166X2017000300423\&lng=en\&nrm=iso>. Acesso em: 08 set. 2017.

MONTERO, Maritza. Fortalecimiento de la Ciudadanía y Transformación Social: Área de Encuentro entre la Psicología Política y la Psicología Comunitaria. Psykhe1 (Santiago), v. 19, n. 2, p. 51-63, 2010. Disponível em: <https://dx.doi.org/10.4067/S0718-22282010000200006>. Acesso em: 9 ago. 2017.

MONTSERRAT, Plaza Aleu; LEONOR, María Cantera Espinosa. El impacto de la violencia de género en la maternidad: entrevistas en profundidad para reflexionar sobre las consecuencias y la intervención. Journal of Feminist, Gender and Women Studies, n. 1, 2015.

NOGUEIRA, Maria da Conceição de Oliveira Carvalho. Os discursos das mulheres em posições de poder. Cad. Psicol. Soc. Trab., v. 9, n. 2, p. 57-72, 2006. Disponível em: $\quad$ http://pepsic.bvsalud.org/scielo.php?script=sci_arttext\&pid=S1516$37172006000200005 \&$ Ing=pt\&nrm=iso >. Acesso em: 21 ago. 2017.

PANKE, Luciana. Campanhas eleitorais para mulheres: desafios e tendências. Curitiba: UFPR, 2016.

PANKE, Luciana.; IASULAITIS, Sylvia. Mulheres no poder: aspectos sobre o discurso feminino nas campanhas eleitorais. Opin. Pública, v. 22, n. 2, p. 385-417, 2016. Disponível em: <http://www.scielo.br/scielo.php?script=sci_arttext\&pid=S010462762016000200385\&Ing=en\&nrm=iso>. Acesso em: 23 ago. 2017.

PEREIRA, Rosângela Saldanha et al. Transversalidade de gênero e políticas sociais no orçamento do estado de Mato Grosso. Rev. Estud. Fem., Florianópolis, v. 18, n. 2 p. 425-450, ago. $2010 . \quad$ Disponível em <http://www.scielo.br/scielo.php?script=sci_arttext\&pid=S0104026X2010000200008\&Ing=pt\&nrm=iso>. Acesso em: 20 ago. 2018.

PIMENTEL FILHO, José Ernesto; RODRIGUES, Mariana Ramos. A política legislativa e a proteção à participação política da mulher no brasil: uma interpretação histórica de processos legislativos. A Barriguda: Revista Científica, [S.I.], v. 7, n. 1, p. 135-157, abr. 2017. ISSN 2236-6695. Disponível em: <http://abarriguda.org.br/revista/index.php/revistaabarrigudaarepb/article/view /340>. Acesso em: 14 set. 2017.

PINTO, Céli Regina Jardim. Feminismo, história e poder. Rev. Sociol. Polit., Curitiba, v. 18, n. 36, p. 15-23, jun. 2010. Disponível em: $<$ http://www.scielo.br/scielo.php?script=sci_arttext\&pid=S0104$44782010000200003 \&$ Ing=en\&nrm=iso >. Acesso em: 17 set. 2017.

PISCOPO, Jennifer M.Capacidad estatal, justicia criminal y derechos políticos. Nueva mirada al debate sobre la violencia contra las mujeres en política. Polít. gob, México, v. 23, n. 2, p. 437-458, dez. 2016. Disponível em: <http://www.scielo.org.mx/scielo.php?script=sci_arttext\&pid=S166520372016000200437\&Ing=es\&nrm=iso>. Acesso em:12 set. 2017. 
PRÁ, Jussara Reis. Mulheres, direitos políticos, gênero e feminismo. Cad. Pagu, n. 43, p. 169-196, $2014 . \quad$ Disponível em: <http://www.scielo.br/scielo.php?script=sci_arttext\&pid=S010483332014000200169\&Ing=en\&nrm=iso>. Acesso em: 21 ago. 2017.

QUINTELA, Débora Françolin; DIAS, Joelson Costa. Participação Política das Mulheres No Brasil: Das Cotas De Candidatura à Efetiva Paridade na Representação. Revista de Teorias da Democracia e Direitos Políticos, v. 2, n. 1, p. 52-74, 2016.

RAMOS, Sandra. El sexismo en la cima: mujeres, liderazgo y poder político. 2016. Página da web. Disponível em: <http://elordenmundial.com/2016/12/19/sexismola-cima-mujeres-liderazgo-poder-politico/>. Acesso em: 21 ago. 2017.

ROSENBLUTH, Frances.; KALLA, Joshua.; TEELE, Dawn. The Female Political Career. 2015. Documento digital. Disponível em: <http://www.womeninparliaments.org/wpcontent/uploads/2015/01/Final_13012015_The-Female-Political-Career.pdf>. Acesso em: 21 ago. 2017

SALGADO, Eneida Desiree; GUIMARÃES, Guilherme Athaides; MONTE-ALTO, Eric Vinicius Lopes Costa. Cotas de Gênero na Política: entre a história, as urnas e o parlamento. Gênero e Direito, v. 4, n. 3, p. 156-182, 2015. Disponível em: <http://periodicos.ufpb.br/index.php/ged/article/view/25973>. Acesso em: 14 ago. 2017.

SILVA, Ociana Donato da; RAICHELIS, Raquel. O assédio moral nas relações de trabalho do(a) assistente social: uma questão emergente. Serv. Soc. Soc., São Paulo, n. 123, p. 582-603, set. $2015 . \quad$ Disponível em: $<$ http://www.scielo.br/scielo.php?script=sci_arttext\&pid=S010166282015000300582\&lng=en\&nrm=iso>. Acesso em: 13 mar. 2018.

SPOHR, Alexandre Piffero et al. Participação Política de Mulheres na América Latina: o impacto de cotas e de lista fechada. Rev. Estud. Fem., Florianópolis, v. 24, n. 2, p. 417-441, ago. $2016 . \quad$ Disponível em: <http://www.scielo.br/scielo.php?script=sci_arttext\&pid=S0104026X2016000200417\&Ing=en\&nrm=iso>. Acesso em: 17 set. 2017.

VENEGAS, Tatiana Rein. Participación política de las mujeres: Aspectos de confluencia entre la ética y los derechos humanos. Acta bioeth., v. 19, n. 2, p. 219228, 2013. Disponível em: $<$ http://www.scielo.cl/scielo.php?script=sci_arttext\&pid=S1726569X2013000200006>. Acesso em: 14 ago. 2017. 
Recebido: 03/04/2019.

Aprovado: 09/07/2019.

DOI: $10.3895 /$ cgt.v12n40.8122

Como citar: BROGNOLI, Paula Caldas; DIAS, Maria Sara de Lima. Política, poder e as implicações de gênero. Cad. Gên. Tecnol., Curitiba, v. 12, n. 40, p. 243-264, jul./dez., 2019. Disponível em:

https://periodicos.utfpr.edu.br/cgt. Acesso em: XXX.

Correspondência:

Paula Caldas Brognoli

Rua Oyapock, 144, apart 602, Curitiba, Paraná, Brasil.

Direito autoral: Este artigo está licenciado sob os termos da Licença Creative Commons-Atribuição 4.0

Internacional.

(c) (1) 